\title{
Review of the safety, efficacy, costs and patient acceptability of recombinant follicle-stimulating hormone for injection in assisting ovulation induction in infertile women
}

This article was published in the following Dove Press journal:

International Journal of Women's Health

25 November 2009

Number of times this article has been viewed

\author{
Marleen Nahuis $1,2,3$ \\ Fulco van der Veen' \\ Jur Oosterhuis ${ }^{2}$ \\ Ben Willem Mol' \\ Peter Hompes ${ }^{3}$ \\ Madelon van Wely' \\ 'Center for Reproductive Medicine, \\ Department of Obstetrics and \\ Gynaecology (H4-205), Academic \\ Medical Center, University \\ of Amsterdam, Amsterdam, \\ The Netherlands; ${ }^{2}$ Department \\ of Obstetrics and Gynaecology, \\ Medisch Spectrum Twente, Enschede, \\ The Netherlands; ${ }^{3}$ Department \\ of Obstetrics and Gynaecology, \\ Free Medical University, Amsterdam, \\ The Netherlands
}

\begin{abstract}
Anovulation is a common cause of female subfertility. Treatment of anovulation is aimed at induction of ovulation. In women with clomiphene-citrate resistant WHO group II anovulation, one of the treatment options is ovulation induction with exogenous follicle-stimulating hormone (FSH or follitropin). FSH is derived from urine or is produced as recombinant FSH. Two forms of recombinant FSH are available - follitropin alpha and follitropin beta. To evaluate the efficacy, safety, costs and acceptability of recombinant FSH, we performed a review to compare recombinant FSH with urinary-derived FSH products. Follitropin alpha, beta and urinary FSH products appeared to be equally effective in terms of pregnancy rates. Patient safety was also found to be comparable, as the incidence of side effects including multiple pregnancies was similar for all FSH products. In practice follitropin alpha and beta may be more convenient to use due to the ease of self-administration, but they are also more expensive than the urinary products.
\end{abstract}

Keywords: follitropin apha, follitropin beta, urinary gonadotropins, polycystic ovary syndrome

\section{Introduction}

Anovulation is a common cause of infertility in women. It is classified by the World Health Organization (WHO) criteria according to endogenous concentrations of serum FSH and estradiol. About $80 \%$ of anovulatory women have WHO type II or normogonadotrophic normoestrogenic anovulation. Polycystic ovary syndrome (PCOS) is the most common form of WHO II anovulatory infertility.

Gonadotropins have successfully been used for ovulation induction in anovulatory women. At present there are two classes of FSH-containing pharmaceutical preparations, those derived from the urine of postmenopausal women and those manufactured with recombinant DNA technology.

Gonadotropins are indicated for the induction of ovulation in the anovulatory infertile patient and for the development of multiple follicles in the ovulatory patient undergoing intra-uterine insemination or participating in an Assisted Reproductive Technology program. ${ }^{1}$

This review aims to evaluate the efficacy, safety and patient acceptability of recombinant gonadotropins in ovulation induction in PCOS women. A short history of the development of the various FSH products is initially described, followed by their pharmacokinetics and isoform profiles. The review then looks into the efficacy,
Center for Reproductive Medicine,

Department of Obstetrics

and Gynaecology (H4-205), Academic

Medical Center, University of Amsterdam,

PO Box 22700, I I 00 DE Amsterdam,

The Netherlands

Tel +3l 023-5663919

Emailm.vanwely@amc.uva.nl 
safety profiles and patient satisfaction of these products used for ovulation induction in comparison with urinary-derived gonadotropins.

\section{Short history of gonadotropins development}

By the late 1950s human pituitary extracts were successfully used for ovulation induction in hypogonadotropic women. ${ }^{2}$ Since then, human-derived gonadotropin preparations have evolved as the mainstay of ovulation induction therapy. The use of pituitary extracts was abandoned because of scarcity of available human pituitary glands and the fear of Creutzveld-Jakob virus.

Pituitary gonadotropins were replaced by urinary derived human menopausal gonadotropins by the early 1960s, when the first report was published on its use for the treatment of ovulatory dysfunction. ${ }^{3}$

Human menopausal gonadotropins consist of a purified preparation of gonadotropins extracted form the urine of postmenopausal women. The generic name is menotropins. They are inactive orally and are given by intramuscular injections. Menotropins were initially only 5\% pure, contained equal amounts of luteinizing hormone (LH) and FSH and large quantities of potentially allergenic urinary proteins.

The next group of gonadotropins to emerge were purified FSH preparations or urofollitropins. Urinary FSH contained less than $1 \%$ LH but was still contaminated with $95 \%$ of nongonadotrophin-related proteins. In the mid 1990s highly purified urinary FSH became available containing less than $0.1 \%$ LH and virtually no urinary proteins, allowing subcutaneous administration. ${ }^{2}$ The production of highly purified FSH was enabled by the development and application of production techniques based on immuno affinity chromatography with monoclonal antibodies.

One cycle of treatment with gonadotropins requires 20 to $30 \mathrm{~L}$ of urine from postmenopausal women. ${ }^{4}$ The increased demand for gonadotropins and the advances in molecular technology lead to the production of recombinant FSH. This was also driven by the fear of infections, for example Creutzveld-Jakob virus, although no infectivity from the urine of humans has ever been detected in four decades of use. ${ }^{5-7}$ However, recombinant follitropins are produced from a hamster cell line and this procedure also bears a theoretical risk of introducing viruses into humans, although again this has never been described. ${ }^{8}$

By transfecting a Chinese hamster ovary cell line with FSH genes recombinant FSH could be stably produced and was introduced in clinical practice in $1992 .{ }^{9}$ Recombinant FSH is homogenous and free of contamination by proteins. Two recombinant preparations are available - follitropin alpha (Gonal $\mathrm{F}^{\circledR}$; Serono Labarotories, Switzerland) and follitropin Beta (Puregon ${ }^{\circledR}$; Schering-Plough Laboratories, the Netherlands).

\section{FSH: pharmacokinetics and isoforms}

FSH is a glycosylated hormone and is composed of two noncovalently linked polypeptide chains, an alpha and a beta subunit. In this heterodimeric structure the alpha and beta subunits confer its biological and immunological activity. The alpha unit is similar to other pituitary and placenta hormones (LH, thyroid-stimulating hormone [TSH] and human chorionic gonadotropin [hCG]). The oligosaccharides in the beta subunit of FSH are highly variable and the composition and complexity of the attached carbohydrate moieties may differ. Each oligosaccharide may show single branched, di- tri- and even tetrabranched structures. ${ }^{10}$ Each branch of the oligosaccharides determines the terminal sialylation of the negatively charged FSH molecule and so a number of isoforms exist. In humans 20 different FSH isoforms have been identified. The liver metabolism of FSH isoforms with a high number of sialic acid residues (ie, acidic isoforms) is considerably lower compared to isoforms with a low content of sialic acid residues (ie, less acidic isoforms). As a consequence, the plasma half-life of the most acidic isoforms is about 240 minutes, while the least acidic isoforms have a plasma half-life of about 180 minutes. ${ }^{11,12}$

The terminal sialylation of human FSH determines the overall charge of the molecule. The iso-electric point can range from 3.5 to $7.0 .^{13}$ The recombinant FSH products differ from the urinary products in that they contain less acidic FSH isoforms. Slightly different purification processes affect the carbohydrate compositions. ${ }^{14}$ The isoform profile of both recombinant preparations are similar, although follitropin alpha is less acidic due to the larger extent of basic isoforms (isoform ranges [4-5] compared with follitropin beta [isoform ranges 3.5-5.5]).

\section{Ovulation induction}

An indication for the use of gonadotropins is anovulation not responding to clomiphene citrate. There are three classes of anovulation, ie, WHO I, WHO II and WHO III. ${ }^{15-17}$ Women with WHO class I anovulation, which accounts for $10 \%$ of anovulatory women, have low or low-normal serum FSH concentrations and low serum estradiol concentrations due to 
decreased hypothalamic secretion of gonadotropin-releasing hormone $(\mathrm{GnRH})$ or pituitary unresponsiveness to $\mathrm{GnRH}$. The causes of hypothalamic amenorrhea include stress- or exercise-related amenorrhea, anorexia nervosa and Kallmann syndrome.

The majority of women with WHO type I anovulation do not have the threshold levels of endogenous LH required to achieve optimal follicular development and steroidogenesis during therapy with FSH alone. ${ }^{17,18}$ Most important is that no term pregnancy occurred with this treatment. In these women an exogenous supply of LH is required to achieve an adequate follicular response. At present women with hypogonadotropic anovulation are most commonly being treated with human menopausal gonadotropin (hMG) or, mostly in a trial context, with a combination of recombinant FSH (rFSH) and LH.

About $80 \%$ of the women that suffer from infertility due to anovulation have WHO class II anovulation. The majority of these women have polycystic ovary syndrome (PCOS). The most recently developed criteria for PCOS require the presence of at least two of the following three criteria: oligo- and or anovulation, hyperandrogenism (clinical or biochemical) and ultrasonic appearance of polycystic ovaria. ${ }^{19}$ The conventional treatment of WHO class II anovulatory women is clomiphene citrate with or without metformin, which will restore ovulation in almost $80 \%$ of women and will result in pregnancy in $50 \%$ of all women. In women with clomiphene resistance and clomiphene failure, gonadotropins are the next line of treatment.

\section{Ovulation induction in women with PCOS}

Ovulation induction with gonadotropins carries a risk for multiple follicular development and multiple pregnancies. A chronic low-dose step-up regimen was introduced to reduce the incidence of these complications. Following spontaneous or progesterone induced bleeding, a course of $37.5 \mathrm{IU}$ to $75 \mathrm{IU}$ of daily FSH treatment is commenced on day 3 of the cycle until ovulation is induced. This starting dose is continued for 14 days. Ovarian response is monitored by transvaginal ultrasound and incremental FSH doses are given until an adequate response has been achieved. If a dominant follicle emerges, the dose of FSH is maintained until the follicle reaches a main diameter of $17 \mathrm{~mm}$ or above. At this point $\mathrm{HCG}$ is injected. With more than 3 dominant follicles the cycle is cancelled. The low-dose step-up protocol has a clinical pregnancy rate of about $20 \%$ per cycle, an incidence of ovarian hyperstimulation syndrome (OHSS) of $1 \%$ to $3 \%$ and a multiple pregnancy rate ranging from $10 \%$ to $25 \% .^{20-23}$

\section{Efficacy, safety and cost of ovulation induction with recombinant $\mathrm{FSH}$; a literature search}

In a Cochrane library meta-analysis from 2001, the efficacy of urinary FSH (uFSH) and rFSH for induction of ovulation was compared in clomiphene resistant anovulatory women. ${ }^{24}$ Three randomized controlled trials were included. Two trials compared follitropin alpha with highly purified uFSH (HP $\mathrm{uFSH})^{25,26}$ and the third trial compared follitropin beta with $\mathrm{HP} \mathrm{uFSH} .{ }^{27}$ No significant differences were found between the two treatment groups in ovulation rate, pregnancy rate, miscarriage, multiple pregnancy rate. The review concluded that there was no evidence of a difference between both $\mathrm{rFSH}$ and HP uFSH for ovulation induction in women with PCOS.

We searched the literature for more recent data. A trial was included if it dealt with the use of follitropin alpha versus follitropin beta or recombinant gonadotropins versus urinary gonadotropins. To identify all relevant trials we searched the Embase (1966 to November 2008) and Medline databases (1988-November 2008).

All randomized controlled trials which included patients with primary or secondary infertility attributed to an ovulation disorder were included in this review.

Unfortunately most studies did not differentiate between women with clomiphene resistance and clomiphene failure, which is why we included both categories in our review.

We considered the following outcome measures after the first treatment cycle:

1. Pregnancy outcomes and ovulation: live birth rate per woman, ongoing pregnancy rate per woman, clinical pregnancy rate per woman and ovulation rate per cycle.

2. Unintended effects: OHSS per cycle, multiple pregnancy rate per woman and local and systemic side effects per woman.

3. Cost-related effects: total dose of gonadotropins administered, duration of gonadotropin treatment.

We identified 9 relevant randomized controlled trials that compared recombinant FSH with urinary gonadotropins. ${ }^{25-33}$ One trial was excluded as it studied differential effects on hemostasis. ${ }^{32} \mathrm{~A}$ further 2 trials were excluded as pregnancy results after 1 treatment cycle could not be extracted. ${ }^{29,33}$ Two trials reported the data of 3 treatment cycles, without reporting the results of the first treatment cycle..$^{29,33}$ 
A detailed description of the 6 trials included in this review is given in Table 1. Four trials compared follitropin alpha with HP urofollitropin. ${ }^{25,26,28,31}$ One trial compared follitropin alpha with highly purified $\mathrm{HMG}^{30}$ and 1 trial compared follitropin beta with HP urofollitropin. ${ }^{27}$ The starting dose in these trials varied between 37 and 75 IU per day.

When at least 2 trials studied a similar comparison, data were pooled and a summary statistic was calculated using a fixed-effects model. For dichotomous data a pooled (odds ration, OR) with $95 \%$ confidence interval (CI) was calculated using the Peto method. For continuous data the mean differences were pooled and mean weighted difference with $95 \%$ CI was calculated. Review Manager Software (RevMan 5, Cochrane Collaboration, Oxford, UK) was used for statistical analysis.

\section{Pregnancy outcomes and ovulation}

All dichotomous outcomes for the trials comparing recombinant gonadotropins and urinary gonadotropins are summarized in Figure 1. None of the included 6 trials found a significant difference for any of the reported pregnancy outcomes.

Four trials reported data on live birth rate per women after the first treatment cycle. Pooling the data resulted in an OR of 1.12 (95\% CI 0.75-1.66) for recombinant gonadotropins versus urinary gonadotropins..$^{25,28,30,31}$

Ongoing pregnancy rate data were reported in 3 trials. ${ }^{27,28,30}$ Pooling the ongoing pregnancy rate data of the 3 trials resulted in an OR of 1.27 (95\% CI 0.78-2.07).

Clinical pregnancy rate data were reported in 3 trials. ${ }^{26,28,30}$ Pooling the clinical pregnancy data of these trials resulted in an OR of 1.13 (95\% CI 0.67-1.89).

All 6 trials reported data on ovulation rate. Pooling these data resulted in a significantly higher ovulation rate after rFSH in comparison to urinary gonadotrophins (OR 1.40; 95\% CI 1.03-1.92). ${ }^{25-28,30,31}$ Hence, significantly more women were ovulatory after the use of recombinant $\mathrm{FSH}$ when compared with urinary preparation, but this did not lead to a higher pregnancy rate. There was no indication for statistical heterogeneity between the trials for any of these outcomes.

\section{Unintended effects}

Since the implementation of the low-dose step-up regimen and the introduction of OHSS management protocols, the major complication of ovarian stimulation is multiple pregnancies. Due to adherence to the cancellation criteria the incidence OHSS is generally low. In the trials OHSS rates

Table I Characteristics of the six included trials

\begin{tabular}{|c|c|c|}
\hline References & Comparison & Population \\
\hline Balen $^{28}$ & $\begin{array}{l}\text { Follitropin alpha vs } \\
\left.\text { HP FSH (Bravelle }{ }^{\circledR}\right)\end{array}$ & $\begin{array}{l}\text { Infertile women with WHO group II anovulation, resistant to CC, with } \\
\mathrm{CC} \text { resistance defined as a failure to ovulate with } \mathrm{CC} \text { of at least } \\
100 \mathrm{mg} / \text { day for } 5 \text { days or failed to conceive after three ovulatory } \\
\text { cycles }(\mathrm{N}=\mid 5 \mathrm{I} \text {, cycles } \mid 5 \mathrm{I}) \text {. Only the first cycle was included }\end{array}$ \\
\hline Revelli ${ }^{31}$ & $\begin{array}{l}\text { Follitropin alpha vs } \\
\left.\text { HP FSH (Metrodin }{ }^{\circledR}\right)\end{array}$ & $\begin{array}{l}\text { Infertile women with WHO group II anovulation, resistant to } \mathrm{CC} \text {, with } \\
\mathrm{CC} \text { resistance defined as a failure to ovulate with incremental doses } \\
\text { of } \mathrm{CC} \text { up to } 200 \mathrm{mg} / \text { day for } 5 \text { days in } 3 \text { treatment cycles }(\mathrm{N}=76 \text {, } \\
\text { cycles } 76) \text { and normo-ovulatory patients with unexplained subfertility } \\
(\mathrm{N}=184,184 \text { cycles). Only the first cycle in included }\end{array}$ \\
\hline Platteau ${ }^{30}$ & $\begin{array}{l}\text { Follitropin alpha vs } \\
\text { HP HMG (Menopur }{ }^{\circledR} \text { ) }\end{array}$ & $\begin{array}{l}\text { Infertile women with WHO group II anovulation, resistant to CC, } \\
\text { with } \mathrm{CC} \text { resistance defined as a failure to ovulate with } \mathrm{CC} \text { of at least } \\
100 \mathrm{mg} / \text { day for } 5 \text { days or failed to conceive after three ovulatory } \\
\text { cycles ( } \mathrm{N}=184 \text {, cycles } 184) \text {. Only the first cycle was included }\end{array}$ \\
\hline Yarali $^{26}$ & $\begin{array}{l}\text { Follitropin alpha vs } \\
\left.\text { HP FSH (Metrodin }{ }^{\circledR}\right)\end{array}$ & $\begin{array}{l}\text { Infertile women with WHO group II anovulation, resistant to CC, with } \\
\text { resistance defined as a failure to ovulate with incremental doses of CC } \\
\text { up to } 150 \mathrm{mg} / \text { day for } 5 \text { days or failure to conceive with the ovulatory } \\
\text { doses of CC during } 6 \text { ovulatory cycles ( } N=51,96 \text { cycles). The first } \\
3 \text { cycles were included }\end{array}$ \\
\hline Coelingh Bennink ${ }^{27}$ & $\begin{array}{l}\text { Follitropin beta vs } \\
\text { HP FSH }\left(\text { Metrodin }^{\circledR} \text { ) }\right.\end{array}$ & $\begin{array}{l}\text { Infertile women with WHO group II anovulation, resistant to CC, } \\
\text { defined as a failure to ovulate during } 3 \text { previous medication cycles or } \\
\text { to conceive during } 6 \text { ovulatory cycles. ( } \mathrm{N}=178 \text { patients, } 36 \text { I cycles). } \\
\text { The first } 3 \text { cycles were included }\end{array}$ \\
\hline Loumaye $^{25}$ & $\begin{array}{l}\text { Follitropin alpha vs } \\
\left.\text { HP FSH (Metrodin }{ }^{\circledR}\right)\end{array}$ & $\begin{array}{l}\text { Infertile women with WHO group II anovulation, resistant to CC } \\
(\mathrm{N}=222)\end{array}$ \\
\hline
\end{tabular}

Abbreviations: CC, clomiphene-citrate; HP FSH, highly purified follicle-stimulating hormone; HP hMG, highly purified human menopausal gonadotropin. 
ranged from zero to $3.2 \%$ per treatment cycle. Most were mild or moderate OHSS, with only one severe OHSS in the whole group of 856 women.

All six randomized trials reported on multiple pregnancies. ${ }^{25,28,30,31}$ Multiple pregnancies occurred in 14 of the 443 women in the recombinant FSH group and in 21 of 419 women in the urinary gonadotropin group (odds ratio 0.68; 95\% CI 0.34-1.36). Most studies reported pregnancy rates after three treatment cycles. Only three trials reported the multiple pregnancy rate after the first treatment cycle. ${ }^{28,30,31}$ Pooling these data also did not reveal significant differences (OR 2.54; 95\% CI 0.58-11.13) (Figure 1).

Local side effects were reported by 5 trials. Bruising, erythema, pain and itching are some of the most commonly reported reactions around the injection site. There were no indications for differences between recombinant or urinary gonadotrophin preparations. However, there were large differences in incidence of the different local reactions between trials ranging from $0 \%$ up to $50 \%{ }^{25,28,30,31,33}$ These large differences between trials were also seen for systemic side effect incidences. The most common systemic side effects were pelvic pain, nausea or headache and the incidences ranged between trials from $0 \%$ to $40 \% .^{25-28,30,31}$

Numerous studies have investigated the impact of fertility treatments on cancer risk in the general population. There is no evidence for an increase in cancer risk with exposure to fertility medication. ${ }^{34,35}$ Furthermore, the use of gonadotropins to induce ovulation does not appear to affect future fecundity.

\section{Economic evaluation of ovulation induction with follitropin alpha}

Besides effectiveness and safety, costs play an important role in deciding which treatment to give to a patient. The relative cost per gonadotropin preparation increases with its purity, but the absolute costs differ between countries.

The cost and effects of follitropin alpha and beta were compared with HP uFSH in 2 randomized controlled trials. ${ }^{29,31}$ The trial comparing follitropin alpha with HP uFSH revealed a significantly lower requirement of FSH when using follitropin alpha (Gonal-F), with mean doses of 844 IU and 668 IU per cycle respectively. ${ }^{29}$ The total costs however were higher for follitropin alpha though this difference was not statistically significant (mean cost per cycle of $€ 208$ for Gonal $F$ versus $€ 175$ for $\mathrm{HP} u F S H)$.

The other trial, comparing follitropin beta and HP $\mathrm{uFSH}$, also found a significantly lower requirement of $\mathrm{FSH}$ when using follitropin beta (Puregon) though there was no indication for a difference in duration of stimulation (mean 10.2 days versus 9.8 days). ${ }^{31}$ The total costs per cycle however were significantly higher for a follitropin beta cycle due to the lower costs per IU of HP uFSH. (mean cost per cycles for follitropin beta was $€ 312$ versus $€ 218$ for HP FSH).

Five trials compared duration of treatment and all six trials compared total the total gonadotrophin dose used. We observed a significantly shorter duration of treatment with rFSH compared with uFSH (weighted mean difference [WMD] minus $1.76 ; 95 \% \mathrm{CI}-2.59$ to -0.93$).{ }^{26-28,30,31}$ Also weighted means for the total FSH dose were lower during treatment with rFSH (WMD -242; 95\% CI -338 to -146).

\section{Patient acceptability}

It is important for patients to choose the product that meets their needs. ${ }^{36}$ Gonadotropins are injected daily for several days in follicular phase and various injection or reconstitution devices are available to facilitate self-injection.

Historically, human derived gonadotropin preparations were administered by intramuscular injections (im).

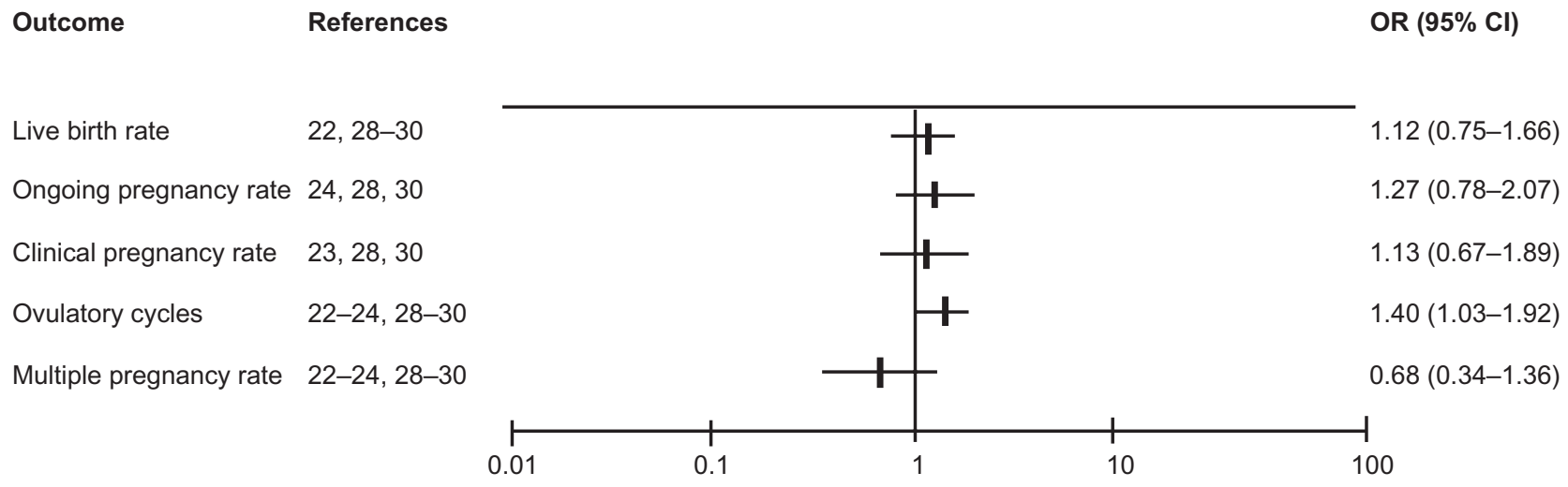

Figure I The studies' pooled odds ratios (OR) for pregnancy outcomes and ovulation rate. Abbreviations: $\mathrm{rFSH}$, recombinant follicle-stimulating hormone; $\mathrm{uFSH}$, urinary follicle-stimulating hormone. 
The introduction of highly purified forms of uFSH and $\mathrm{rFSH}$ enabled subcutaneous injection which is less painful than im administration.

In several studies the follitropin alpha and follitropin beta injection pen was compared to a conventional device. A pen was easier to use, more convenient and less painful compared to conventional syringe and vials. ${ }^{36-38}$

Patient and nurse satisfaction of follitropin alpha compared to beta were assessed in 2 randomized controlled trials. In a pilot study among 31 patients, most women favored the follitropin alpha pen over the earlier-used follitropin beta pen because preparation was faster; they were more confident of accurate dosing and had to make fewer dose adjustments. Comparable results were found in another trial among 140 women and nurses. ${ }^{39}$

\section{Discussion}

In this review we evaluated the efficacy, side effects, costs and patient acceptability of follitropin alpha and beta in ovulation induction in mainly WHO class II anovulatory women. On basis of the current best available evidence we found no differences in pregnancy and safety outcomes between the recombinant forms of FSH and urinary gonadotropins.

Both recombinant and urinary preparations are acceptable for patients. There are no indications that patients prefer one preparation over the other. The patient acceptability appears to be mainly influenced by the mode of administration.

The advantage of recombinant FSH over the urinaryderived FSH products is that small doses can easily be applied without having to use half ampoules. Furthermore there are no problems with its availability, while large quantities of urine from menopausal women are required for urofollitropin production.

The bioactivity and glycoform profile is of interest when comparing cost effectiveness. The more basic rFSH would have a higher biopotency, but this is beneficial only when it translates into lower doses of gonadotropins used and a shorter duration of stimulation leading to lower costs. Indeed, we showed in this review that the use of recombinant gonadotropins leads to a lower dosage requirement and a slightly shorter stimulation period. On the other hand, $\mathrm{rFSH}$ is more expensive than urinary-derived FSH products. The costs per cycle of $r$ FSH and HP FSH were compared in 2 trials and in both the cost per cycle were higher for $\mathrm{rFSH}$ even though in both trials a lower FSH dose could be used. ${ }^{31}$

When comparing the effectiveness of $\mathrm{rFSH}$ and $\mathrm{uFSH}$ the differences between women with clomiphene resistance and clomiphene failure are of interest. These women probably have different fertility prospects. An individual patient data metaanalysis would be needed to differentiate between women with clomiphene resistance and clomiphene failure.

In conclusion there were no indications of a difference in effectiveness, safety and tolerability between recombinant and urinary follitropins. Follitropin alpha and beta may be more convenient to use due to the ease of self-administration, but they are also more expensive than the urinary products. Any choice the clinician makes on what gonadotropin to use for ovulation induction is a good one.

\section{Disclosures}

The authors received no funding for writing this manuscript, and declare no conflicts of interest.

\section{References}

1. Hull MG, Glazener CM, Kelly NJ, et al. Population study of causes, treatment, and outcome of infertility. Br Med J (Clin Res Ed). 1985;291:1693-1697.

2. Gemzell CA, Diczfalusy E, Tillinger G. Clinical effect of human pituitary follicle-stimulating hormone (FSH). J Clin Endocrinol Metab. 1958;18:1333-1348.

3. Lunenfeld B, Menzi A, Volet B. Clinical effects of a human postmenopausal gonadotropin. Rass Clin Ter. 1960;59:213-216.

4. Balen AH, Hayden CJ, Rutherford AJ. What are the clinical benefits of recombinant gonadotrophins? Clinical efficacy of recombinant gonadotrophins. Hum Reprod. 1999;14:1411-1417.

5. Reichl H, Balen A, Jansen CA. Prion transmission in blood and urine: what are the implications for recombinant and urinary-derived gonadotrophins? Hum Reprod. 2002;17:2501-2508.

6. Shaked GM, Shaked Y, Kariv-Inbal Z, Halimi M, Avraham I, Gabizon R. A protease-resistant prion protein isoform is present in urine of animals and humans affected with prion diseases. J Biol Chem. 2001;276:31479-31482.

7. Serban A, Legname G, Hansen K, Kovaleva N, Prusiner SB. Immunoglobulins in urine of hamsters with scrapie. J Biol Chem. 2004;279:48817-48820.

8. Gleicher N, Vietzke M, Vidali A. Bye-bye urinary gonadotrophins? Recombinant FSH: a real progress in ovulation induction and IVF? Hum Reprod. 2003;18:476-482.

9. Albano C, Smitz J, Camus M, Coelingh Bennink H VSA, Devroey P. Pregnancy and birth in an in vitro fertilisation cycle after controlled ovarian stimulation in a women with a histroy of allergic reactions to human menopausal gonadotropins. Hum Reprod. 1996;11(8):1632-1634.

10. Hard K, Mekking A, Damm JB et al. Isolation and structure determination of the intact sialylated N-linked carbohydrate chains of recombinant human follitropin expressed in Chinese hamster ovary cells. Eur $J$ Biochem. 1990;193:263-271.

11. Barrios-De-Tomasi J, Timossi C, Merchant H, et al. Assessment of the in vitro and in vivo biological activities of the human follicle-stimulating isohormones. Mol Cell Endocrinol. 2002;186:189-198.

12. Creus S, Chaia Z, Pellizzari EH, Cigorraga SB, Ulloa-Aguirre A, Campo S. Human FSH isoforms: carbohydrate complexity as determinant of in-vitro bioactivity. Mol Cell Endocrinol. 2001;174:41-49.

13. Ulloa-Aguirre A, Zambrano E, Timossi C, et al. On the nature of the follicle-stimulating signal delivered to the ovary during exogenously controlled follicular maturation. A search into the immunological and biological attributes and the molecular composition of two preparations of urofollitropin. Arch Med Res. 1995;26 Spec No:S219-S230. 
14. Gordon K. New developments in gonadotrophin pharmacology. Reprod Biomed Online. 2002;5:259-264.

15. World Health Organisation. WHO manual for the standardized investigation and diagnosis of the infertile couple. Cambridge: Cambridge University Press; 1993.

16. ESHRE Capri Workshop Group. Mono-ovulatory cycles: a key gole in profertility programmes. Hum Reprod Update. 2003;9:263-274.

17. Rowe PJ, Comhaire FA, Hargreave TB, Mellow HJ. WHO manual for the standardized investigation and diagnosis of the infertile couple. Cambridge: Cambridge University Press. 1997;1-80.

18. Kousta E, White DM, Piazzi A, Loumaye E, Franks S. Successful induction ovulation and completed pregnancy using recombinant human luteinizing hormone and follicle stimulating hormone in a woman with Kallmann's syndrome. Hum Reprod. 1996;11:70-71.

19. Rotterdam ESHRE/ASRM-Sponsored PCOS consensus workshop group. Revised 2003 consensus on diagnostic criteria and long-term health risks related to polycystic ovary syndrome (PCOS). Hum Reprod. 2004;19:41-47.

20. Homburg R, Howles CM. Low-dose FSH therapy for anovulatory infertility associated with polycystic ovary syndrome: rationale, results, reflections and refinements. Hum Reprod Update. 1999;5:493-499.

21. Speroff. The Clinical Gynecologic Endocrinology and Infertility. 7 ed. 2004:897-930.

22. Hugues JN, Cedrin-Durnerin I, Howles CM, et al. The use of a decremental dose regimen in patients treated with a chronic low-dose step-up protocol for WHO Group II anovulation: a prospective randomized multicentre study. Hum Reprod. 2006;21:2817-2822.

23. Balen AH, Platteau P, Andersen AN, et al. The influence of body weight on response to ovulation induction with gonadotrophins in 335 women with World Health Organization group II anovulatory infertility. BJOG. 2006;113:1195-1202.

24. van Wely M, Bayram N, van der Veen F. Recombinant FSH in alternative doses or versus urinary gonadotrophins for ovulation induction in subfertility associated with polycystic ovary syndrome: a systematic review based on a Cochrane review. Hum Reprod. 2003;18:1143-1149.

25. Loumaye E, Martineau I, Piazzi A, et al. Clinical assessment of human gonadotrophins produced by recombinant DNA technology. Hum Reprod. 1996;11 Suppl 1:95-107.

26. Yarali H, Bukulmez O, Gurgan T. Urinary follicle-stimulating hormone (FSH) versus recombinant FSH in clomiphene citrate-resistant, normogonadotropic,chronic anovulation: a prospective randomized study. Fertil Steril. 1999;72:276-281.

27. Coelingh Bennink HJ, Fauser BC, Out HJ. Recombinant folliclestimulating hormone (FSH; Puregon) is more efficient than urinary FSH (Metrodin) in women with clomiphene citrate-resistant, normogonadotropic, chronic anovulation: a prospective, multicenter, assessor-blind, randomized, clinical trial. European Puregon Collaborative Anovulation Study Group. Fertil Steril. 1998;69:19-25.
28. Balen A, Platteau P, Andersen AN, Devroey P, Helmgaard L, Arce JC. Highly purified FSH is as efficacious as recombinant FSH for ovulation induction in women with WHO Group II anovulatory infertility: a randomized controlled non-inferiority trial. Hum Reprod. 2007;22:1816-1823.

29. Gerli S, Casini ML, Unfer V, Costabile L, Mignosa M, Di Renzo GC. Ovulation induction with urinary FSH or recombinant FSH in polycystic ovary syndrome patients: a prospective randomized analysis of cost-effectiveness. Reprod Biomed Online. 2004;9:494-499.

30. Platteau P, Andersen AN, Balen A, et al. Similar ovulation rates, but different follicular development with highly purified menotrophin compared with recombinant FSH in WHO Group II anovulatory infertility: a randomized controlled study. Hum Reprod. 2006;21:1798-1804.

31. Revelli A, Poso F, Gennarelli G, Moffa F, Grassi G, Massobrio M. Recombinant versus highly-purified, urinary follicle stimulating hormone (r-FSH vs HP-uFSH) in ovulation induction: a prospective, randomized study with cost minimization analysis. Reprod Biol Endocrinol. 2006; 18 (4):38.

32. Ricci G, Cerneca F, Simeone R, et al. Impact of highly purified urinary FSH and recombinant FSH on haemostasis: an open-label, randomized, controlled trial. Hum Reprod. 2004;19:838-848.

33. Szilagyi A, Bartfai G, Manfai A, Koloszar A, Pal A, Szabo I. Low dose ovulation induction with urinary gonadotropins or recombinant follicle stimulating hormone in patients with polycystic ovary syndrome. Gynecol Endocrinol. 2004;18:17-22.

34. Klip H, Burger CW, Kenemans P, van Leeuwen FE. Cancer risk associated with subfertility and ovulation induction: a review. Cancer Causes Control. 2000;11(4):319-344.

35. Salhab M, Al Sarakbi W, Mokbel K. In vitro fertilization and breast cancer: a review. Int J Fertil Womens Med. 2005;50(6):259-266.

36. Weiss N. Gonadotrophin products: empowering patients to choose the product that meets their needs. Reprod Biomed Online. 2007;15 (1): 31-37.

37. Somkoti SG, Schertz JC, Moore M, Ferrande L, Kelly E, The gonal-F prefilled pen in OI study 24785 group. Patient experience with follitropin alfa prefilled pen versus previously used injectable gonadotropins for ovulation induction in oligoanovulatory women. Curr Med Res Opin. 2006;22(10):1981-1986.

38. Aghssa MM, Azargoon A, Ramezanzadeh F, Bagheri M. A comparison of the efficacy, tolerability, and convenience of two formulations of follitropin-alpha in Iranian woman undergoing intracytoplasmic sperm injection cycles. Fertil Steril. 2008;90:1043-1048.

39. Porter R, Kissel C, Saunders H, Keck C. Patients and nurse evaluation of recombinant follicle stimulating hormone administration methods: a comparison of two follitropin injection pens. Curr Med Res Opin. 2008;24(3):727-735.
International Journal of Women's Health

\section{Publish your work in this journal}

The International Journal of Women's Health is an international, peerreviewed open-access journal publishing original research, reports, reviews and commentaries on all aspects of women's healthcare including gynaecology, obstetrics, and breast cancer. Subject areas include: Chronic conditions (migraine headaches, arthritis, osteoporosis);

\section{Dovepress}

Endocrine and autoimmune syndromes; Sexual and reproductive health; Psychological and psychosocial conditions. The manuscript management system is completely online and includes a very quick and fair peer-review system. Visit http://www.dovepress.com/ testimonials.php to read real quotes from published authors. 